\title{
Dijital Fleksibl Üreterorenoskoplar
}

\author{
Volkan Ülker', Hasan Anıl Atalay², illter Alkan², Fatih Altunrende²
}

${ }^{1}$ Sağlık Bilimleri Üniversitesi, Tepecik Eğitim ve Araştırma Hastanesi, Üroloji Kliniği, İzmir

${ }^{2}$ Sağlık Bilimleri Üniversitesi, Okmeydanı Eğitim ve Araştırma Hastanesi, Üroloji Kliniği, İstanbul

\section{Giriş}

Fleksibl üreteroskopun (f-URS) kullanımı ilk kez 1964 y yllında fiberoptik pediatrik sistoskopla erişkinde üst üriner sistemin (ÜÜS) görüntülenmesiyle Marshall tarafından bildirilmiştir (1). Uzunca bir süre klinik kullanım alanında bir gelişim yaşanmamasının ardından defleksiyon sistemlerinin eklenmesiyle 1987 yılında Bagley tarafından klinik uygulaması yayınlanmıştır (2). Başlangıçta tanısal amaçla kullanımindan sonra holmiyum:YAG (Ho:YAG) lazer ve teknolojideki gelişmelerle birlikte f-URS ÜÜS patolojilerinin tanı ve tedavisinde son 20 yılda önemli bir ilerleme sağlamıştır. Üst üreter ve böbrek taşları, ÜSS tümörleri ve darlıkları bu sayede daha non-invazif bir şekilde tedavi edilebilir hale gelmiştir. Özellikle vücut-dışı şok-dalgası litotripsisi (ESWL) tedavisine dirençli $2 \mathrm{~cm}$ 'e kadar olan böbrek taşları ve soliter böbrekteki ÜÜS tümörlerinin tedavisinde f-URS vazgeçilmez bir konuma gelmiştir. Teknolojideki gelişimle birlikte f-URS aletlerinin çapı ufalmış, görüntü kaliteleri, defleksiyon ve manevra kabiliyetleri artmış, ek olarak çalışma kanalları da genişlemiştir. Başlangıçta litotripsi için sadece elektro-hidrolik sistemler kullanılabilirken Ho:YAG lazerlerin geliştirilmesi, kullanılan kılavuz tel, üreteral akses kılıfı (UAS) ve forsepslerin minyatürleşmesi, kalitelerinin artması böbrek taşlarının tedavisinde f-URS'nin giderek daha fazla kullanılmasını ve endikasyonlarının artmasını sağlamıştır. Görüntü teknolojisindeki ilerlemeler sonucunda fiberoptik f-URS'lerin ardından dijital f-URS'ler geliştirilmiştir. Gününüzde dijital sistemler giderek daha fazla kullanılmaktadır. Bu yazıda dijital f-URS'lerin özellikleri, avantajları ve limitasyonları özetlenmeye çalışılmıştır.

\section{Fiberoptik görüntüleme}

Fiberoptik f-URS aletlerde demet şeklinde dizilen ve 1şı̆̆ ileten çok sayıdaki fiberler distal ve proksimal uçta bulunan lensler sayesinde bir teleskop oluşturmakta ve görüntüyü büyütmektedir. Ayrı bir ışık kaynağı ve proksimal uca takılan bir kamera ile görüntü video sistemine ve ekrana iletilmektedir. Ancak fiberoptik sisteminde her bir lifin bağımsız olarak görüntüyü iletmesinden dolayı iletilen görüntü balpeteği yada sinek gözü görünümünde olmaktadır. Bu durum rijid ve semi-rijid URS'ler ile karşılaştırıldığında daha düşük bir görüntü kalitesine neden olmaktadır. Ek olarak, defleksiyonda kullanım arttıkça zamanla fiberoptik demet içindeki fiberler kopmakta, kopan fiberler ışığı iletemediğinden görüntüde siyah noktalar ve boşluklar meydana gel- mektedir. Yapılan bir çalışmada fiberoptik f-URS ile ortalama 15.3 kullanım sonrası en az 20 optik fiberin hasar gördüğünü gösterilmiştir (3). Fiberlerdeki hasar arttıkça görüntü kalitesi de tamir gerekene kadar azalmaya devam etmektedir. Fiberoptik cihazlardaki bir başka da sorun sıvı sızıntısına bağlı buğu oluşumudur.

\section{Dijital görüntüleme}

Son yıllarda dijital görüntülemenin ve teknolojinin gelişmesi sayesinde dijital f-URS aletleri geliştirilmiş ve operasyonların fiberoptik f-URS'lere kıyasla daha yüksek görüntü kalitesinde yapılabilmesi sağlanmıştır (4). Dijital endoskoplarda "chip on the tip" teknolojisi sayesinde görüntü aletin ucundaki dijital CCD veya CMOS mikrosensör tarafından algilanıp tek bir fiber vasitasıyla proksimale iletilir. Proksimaldeki sensör görüntüyü işler. Işık distaldeki bir LED 1şık kaynağı yada proksimal bir kaynaktan iletilebilir. CMOS sensörler daha az enerji kullanırlar, görüntü işleme daha hızlıdır, daha serin ortamda çalışırlar ve CCD sensörlere göre maliyetleri daha düşüktür. Buna karşın CCD görüntüleme daha oturmuş bir teknolojidir, sinyal kirliliğinden daha az etkilenir ve daha yüksek hassasiyete sahiptir. Bazen dijital f-URS'lerde uca yakın lazer kullanımı sırasında foto-akustik etki ile görüntü distorsiyonu oluşabilmektedir. Dijital f-URS’ler yüksek çözünürlüklü görüntü, oto-fokus kapasitesi ve dijital büyütme özellikleri sunarlar. Görüntü tek bir fiberden iletildiğinden fiberoptik f-URS'lerdeki bal peteği görüntüsü olmaz (Resim 1). Bunun sonucunda yüksek görüntü kalitesi ve fiberoptik f-URS'e kıyasla 3 kat daha büyük ekran görüntüsü sağlarlar (5). Tüm CMOS sensörlü dijital f-URS'ler entegre LED 1şık kaynağı kullanırlar ki bu da eksternal bir

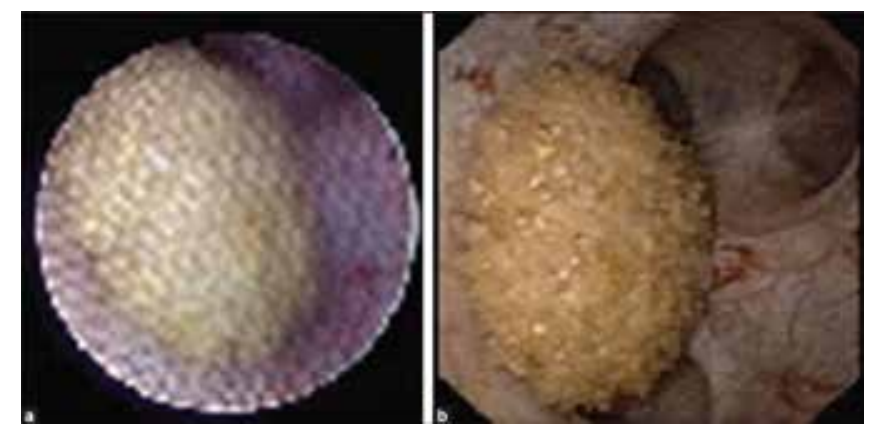

Resim 1: Fiberoptik ve dijital f-URS arasındaki görüntü kalitesi fark1 
1şık kaynağına ihtiyacı ortadan kaldırır. Xenon 1şık kaynakları ise çıkardıkları 1sı sebebiyle dikkat edilmezse yanıklara sebep olabilir. Olympus modellerinde ise Xenon 1şık kaynağ kullanılmasına rağmen entegre kablo nedeniyle böyle bir risk mevcut değildir. İlk dijital f-URS olan Invisio ${ }^{\circledR}$ DUR ${ }^{\circledR}$-D (Gyrus-ACMI) 2006 yılında piyasaya çıkmıştır. Halen piyasada 6 adet dijital tekrar kullanılabilir f-URS bulunmaktadır.

\section{TARTIŞMA}

Özellikle son 10 yılda görüntü teknolojisindeki gelişmelerin medikal aletlere yansımasından f-URS'ler de nasibini almış ve entegre sistemler geliştirilmiştir. Fiberoptik aletlerden farklı olarak dijital f-URS'lerde kamera ve işık kaynağının URS ile birleşik olması (Resim 2) kablo karmaşasını ortadan kaldırmakta, aletin daha hafif olması da uzun süren operasyonlarda cerrahın komforu açısından avantaj yaratmaktadır (6). Örnek olarak, dijital özellikteki Gyrus-ACMI Invisio DUR-D sadece 505g iken fiberoptik özellikteki DUR-8 Elite ise $1012 \mathrm{~g}$ ağırlığındadır.

f-URS'lerin önemli bir kullanım alanı ÜÜS tümörlerinin tanı ve tedavisidir. Fiberoptik f-URS'lerde standart olarak beyaz ışık kullanılmaktadır. Çok küçük olmayan ÜÜS lezyonlarının tanısı için beyaz ışık ile görüntüleme yeterlidir, ancak küçük ve düz lezyonların saptanmasında

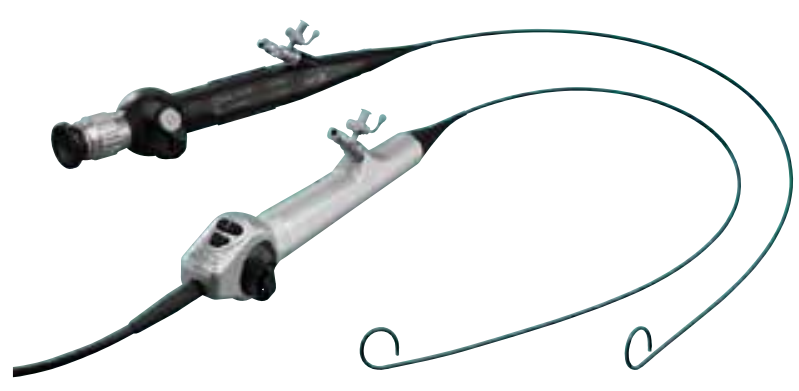

Resim 2: f-URS'de gövdeye entegre kamera zorluk olabilmektedir. "Narrow band" görüntüleme (NBI) veya Fotodinamik tanı (PPD) bu tip neoplazik lezyonların saptanmasında avantaj sağlamaktadır. Bu teknoloji dijital f-URS ile birlikte kullanılabilmektedir. NBI teknolojisi beyaz 1şı ̆̆ 1 hemoglobin tarafından absorbe edilebilen daha dar band genişliği olan 415 nm'lik mavi ve 540 nm'lik yeşil olmak üzere iki ışığa filtrelemektedir. Bu da mukoza yüzeyi ile mikro-vasküler yapılar arasında bir kontrast yaratarak boya verilmesine gerek olmaksızın küçük, düz lezyonların tanınmasını kolaylaştırmaktadır (7). Traxer ve ark. tarafından yapılan ve 27 hastayı içeren bir çalışmada beyaz ışıkta saptanamayan 5 ek tümör daha NBI kullanılabilen URF-V dijital f-URS sayesinde saptanabilmiştir (8). Bu durum ÜÜS tümörlerini saptamada yaklaşık \%23 oranında ek katkı sağlamaktadır. NBI teknolojisi dijital URS'ler içinde sadece dijital Olympus modellerinde mevcuttur. Benzer şekilde Karl Storz FLEX-X ${ }^{c}$ serisinde yazılım bazlı olarak görüntü zenginleştirmeyi sağlayan Clara $^{\mathrm{TM}}$ ve Chroma $^{\mathrm{TM}}$ sistemleri ile yine NBI'e benzer şekilde renk ayrımı ile görünmesi zor lezyonların daha rahat tespit edilmesini sağlayan Spectra $^{\mathrm{TM}}$ görüntü sistemi bulunmaktadir.

Mevcut 6 dijital f-URS arasındaki teknik farklar Tablo 1 'de gösterilmiştir. Henüz dijital f-URS'leri kendi aralarında kıyaslayan yeterli sayıda çalışma mevcut değildir. Shah ve ark. tarafından 2015'de yapılan ve Gyrus-ACMI Invisio DUR-D ile Olympus URF-V'yi kıyaslayan çalışmada toplam 101 hasta randomize olarak 2 gruba ayrılmıştır. Görüntü kalitesi ve manevra kabiliyeti açısından yapılan kıyaslamada URF-V daha üstün bulunurken dayanıklılık aşısından heriki f-URS arasında fark bulunamamıştır (9). Genel olarak dijital f-URS'lerin en büyük dezavantajı olarak distal uçlarının fiberoptik aletlere göre daha uzun ve kalın olması gösterilmektedir. Özellikle dar infindibulum mevcudiyetinde dijital f-URS'lerin nispeten geniş çapı kalikse girişte zorluk yaratabilmektedir. Dijital f-URS'lerin proksimal kılıf çap1 8.5-9.9F arasında değişirken, fiberoptik f-URS çapları 5.3-8.7F arasında değişmektedir (10). Bu durum akla dijital f-URS'lerde intrarenal manevra açısından bir dezavantaj olup olmayacağını

Tablo 1: Tekrar kullanılabilen dijital f-URS'lerin teknik özelliklerinin karşılaştırılması

\begin{tabular}{|c|c|c|c|c|c|c|}
\hline Model & Üretici & $\begin{array}{l}\text { Distal uç } \\
\text { çapı (F) }\end{array}$ & $\begin{array}{c}\text { Proksimal kılıf } \\
\text { çapı (F) }\end{array}$ & $\begin{array}{c}\text { Primer } \\
\text { defleksiyon } \\
\text { derecesi } \\
\text { (yukarı/aşağı) }\end{array}$ & $\begin{array}{c}\text { Çalışma } \\
\text { kanalı (F) }\end{array}$ & Ek özellik \\
\hline Invisio DUR-D & $\begin{array}{l}\text { Gyrus-ACMI } \\
(\mathrm{ABD})\end{array}$ & 8.7 & 9.3 & $250 / 250$ & 3.6 & - \\
\hline FLEX-Xc & $\begin{array}{l}\text { Karl Storz } \\
\text { (Almanya) }\end{array}$ & 8.5 & 9.5 & $270 / 270$ & 3.6 & $\begin{array}{c}\text { Spectra, } \\
\text { Clara, Chroma }\end{array}$ \\
\hline URF-V & $\begin{array}{l}\text { Olympus } \\
\text { (Japonya) }\end{array}$ & 8.5 & 9.9 & $180 / 275$ & 3.6 & NBI \\
\hline URF-V3 & $\begin{array}{l}\text { Olympus } \\
\text { (Japonya) }\end{array}$ & 8.4 & 8.5 & $275 / 275$ & 3.6 & NBI \\
\hline BOA Vision & $\begin{array}{l}\text { Richard Wolf } \\
\text { (Almanya) }\end{array}$ & 6.6 & 8.9 & $270 / 270$ & 3.6 & - \\
\hline COBRA Vision & $\begin{array}{l}\text { Richard Wolf } \\
\text { (Almanya) }\end{array}$ & 5.2 & 9.9 & $270 / 270$ & $2.4+3.6$ & Dual lümen \\
\hline
\end{tabular}

$\mathrm{NBI}=$ Narrow band Imaging 
getirmektedir. Fiberoptik ve dijital f-URS'lerin manevra kabiliyeti ve taşsızlık oranı bakımından kıyaslayan 118 hastalık bir çalışmada pyelokaliseal sisteme ulaşabilme oranı fiberoptik ve dijital f-URS'lerde sırasıyla \%98 ve \%94 olarak olarak bulunurken işlem süresi fiberoptik f-URS kullanılan vakalarda belirgin olarak daha uzun bulunmuştur (11). Ülkemizde yapılan çalışmalar arasında Ülker ve ark. fiberoptik GyrusACMI DUR-8 Elite ile hedef kalikse ulaşma oranını \%100 olarak bulunmuştur (12). Yine Binbay ve ark. tarafından yapılan 76 hastalık bir çalışmada ise tüm pyelokaliseal sisteme ulaşım oranı fiberoptik f-URS ile \%97 iken bu oran dijital f-URS kullanımında \%90.4'e düşmektedir (13). Diğer çalışmalarla benzer şekilde operasyon süresi dijital f-URS kullanımında belirgin daha düşüktür. Bu durum manevra kabiliyetinin k1smen daha zor olduğu kabul edilen dijital f-URS'lerin fiberoptik olanlar ile manevra açısından kıyaslanabilir olduğu gösterirken görüntü kalitesindeki yüksekliğin operasyon süresi üzerinde olumlu etki yaptığını da göstermektedir. Multescu ve ark. 44 hastalık bir çalışmada dijital Olympus URF-V ile fiberoptik Storz FLEX-X model f-URS'lerin kıyaslamasını yapmış, dijital URF-V ile daha üstün manevra kabiliyeti ve görüntü kalitesi olduğu sonucuna varmışlardır. Ancak dijital URF-V'nin geniş çapı dar infindibulum girişlerine izin vermemiştir (14). Al-Qahtani ve ark. vakaların \%10'unda dar infindibulum nedeniyle alt kaliks girişi yapılamadığını ancak aynı görevin distal ucu 5.3F olan fiberoptik URF-P5 (Olympus) ile başarılabildiğini belirtmişlerdir (5). f-URS'lerin manevra kabiliyetini belirleyen önemli bir husus da defleksiyon oranlarıdır. Aletlerde aktif olarak yukarı ve aşağı defleksiyon özelliliği bulunmaktadır. Defleksiyon oranlarını incelediğimizde dijital f-URS'lerin fiberoptikler ile kıyaslabilir düzeyde olduğunu görebiliriz. Yukarı/aşağı defleksiyon oranları dijital f-URS'lerde 180-275/250-275 arasindayken, fiberoptik f-URS'lerde 170-275/120-275 arasındadır (Tablo 1). Ancak aktif sekonder defleksiyon mekanizması f-URS'ler içinde sadece fiberoptik özellikteki DUR-8 Elite modelinde mevcuttur ki bu da özellikle alt kaliks işlemlerinde manevra kolaylığı sağlayabilmektedir. f-URS ile ÜÜS erişimi kılavuz tel üzerinden yada UAS yardımı ile yapılabilmektedir. Dijital f-URS'lerin distal çapının daha kalın olması UAS kullanım ihtiyacını arttırabilmektedir. Bach ve ark. tarafından yapılan bir çalışmada fiberoptik aletlere göre dijital olanlarda belirgin derecede daha fazla UAS kullanım oranı olduğu bildirilmiştir (15). Diğer taraftan UAS kullanımının avantajları da mevcuttur. UAS kullanımı daha düşük irrigasyon basıncında çalışmaya imkan vermekte, bundan dolayı üreteral veya forniseal rüptür riskini azaltmakta, operasyon süresini ve skopi kullanım süresini ise azaltmaktadır $(16,17)$. Fiberoptik ve dijital f-URS'lerin klinik performanslarını mukayese eden Somani ve ark. tarafından yapılan bir çalışmada fiberoptik Olympus URF-P6 ile postoperatif 1.ayda \%86 taşsızlık oranı bulunurken dijital URF-V ile \%88.2 taşsızlık oranına ulaşılmıştır (11). Ülkemizde Binbay ve ark. tarafından yapılan bir çalışmada da klinik başarı açısından fiberoptik ve dijital aletler arasında fark bulunmamış ancak operasyon süresi dijital f-URS grubunda belirgin daha kısa bulunmuştur (11).

Genel olarak f-URS aletlerinin kırılgan bir yapısı vardır. $\mathrm{Bu}$ durum aletin yüksek maliyetinin yanı sıra sürekli tamir yada yenileme masraflarını da beraberinde getirmektedir. f-URS'lerde en sık görülen problemler arasında defleksiyon mekanizmalarında oluşan bozukluklar, lazer fiberinin URS ucundan tam çıkarılmadan ateşleme yapılması yada çalışma kanalına sokulan enstrümanlar nedeniyle aletin iç kısmının hasar görmesi sayılabilir. Dijital f-URS'de olan Endoscope Protection System (EPS) lazer fiberi f-URS'nin içindeyken CMOS sensör ile haberleşerek ateşlemeyi engellemekte ve lazer enerjisinden aletin hasar görmesinin önüne geçmektedir. Yapılan çalışmalarda bu sistemin \%100 etkin olduğu saptanmıştır $(18,19)$. Bu sistem Gyrus-ACMI Invisio DUR-D ile kullanılabilmektedir. Tüm f-URS'lerin kısıtlı bir ömrü vardır. Alet kullanıldıkça defleksiyon mekanizmasında yorulma ve kopmalar meydana gelmektedir. İlk jenerasyon fiberoptik f-URS'lerde 6-16 kullanım (ortalama 12) yada 3-12.8 saat kullanım sonrası tamir ihtiyacı bildirilmiştir (20, 21). Yeni jenerasyon fiberoptik f-URS'lerde ise daha uzun kullanım süreleri sağlanabilmektedir. Traxer ve ark. Storz FLEX-X model fiberoptik f-URS ile 50 kullanıma ulaştıklarını belirtmişlerdir (22). Dijital f-URS'lerin kullanım ömürleri konusunda henüz yeterli çalışma olmamakla birlikte Al-Qahtani ve ark. Olympus URF-V ile 60 kullanım (5), Shah ve ark. ise Gyrus-ACMI DUR-D ile ortalama 11.26, URF-V ile ise ortalama 14 kullanım sonra tamir ihtiyacı olduğunu bildirmişlerdir (9). Türkiye'den Binbay ve ark. tarafından ise tamire kadar fiberoptik f-URS ile ortalama 17, dijital f-URS ile ise ortalama 21 kullanım bildirilmiştir (13). f-URS'lerdeki sık görülen bir sorun aletin kullanıldıkça defleksiyon mekanizmalarında oluşan yorgunluktur. Bu durum dijital ve fiberoptik aletlerde benzer oranda görülmektedir. Mustescu ve ark. yaptıkları bir çalışmada 22 kullanım sonunda fiberoptik f-URS'de \%10, dijital f-URS'de ise \%0 oranında defleksiyon kaybı saptarken (14) yaptıkları diğer çalışmada ise iki dijital f-URS'yi kıyaslamış, 30'şer (20 terapötik, 10 tanısal) kullanım sonunda Olympus URF-V'de \%5, Storz FLEX-Xc'de ise \%9 oranında defleksiyon kaybı olduğunu belirtmişlerdir (23). Aletin defleksiyon halinde kullanım süresi uzadıkça ömrü de kısalmaktadır. Henüz sağlıklı bir kıyaslama yapmak için yeterli sayıda çalışma bulunmasa da görünen, yeni jenerasyon fiberoptik f-URS'ler ile dijital f-URS'lerin kullanım ömürleri arasında belirgin bir fark olmadığ 1 yönündedir. Ancak dijital f-URS'lerde operasyon süresinin nispeten daha kısa olması aletin kullanım saati açısından avantajlı olabilir. Diğer taraftan, yine Multescu ve ark. 3 yeni Storz FLEX-Xc ile yaptıkları bir çalışmada alt pol taşlarında re-lokasyon, aleti AUS ile çıkarma şeklinde tekniklerle 3. aletin kullanımını 150 kullanıma kadar çıkarabilmişlerdir (24).

Mevcut 6 dijital f-URS arasındaki teknik farklar Tablo 1'de gösterilmiştir. Gövde kılıf çapı 8.5F ile en ince olan Olympus URF-V3'dür. Distal uç bakımından Wolf BOA Vision (6.6F) ve COBRA Vision (\%5.2F) en ince distal uca sahip aletlerdir. Ancak distal ucu en ince olan Wolf COBRA Vision olmasina rağmen dual lümene sahip olması nedeniyle proksimal kılıf çapı 9.9F'e ulaşmaktadır. Henüz dijital f-URS'leri kendi aralarında kıyaslayan yeterli sayıda invivo çalışma mevcut değildir. Shah ve ark. tarafından 2015'de yapılan ve GyrusACMI Invisio DUR-D ile Olympus URF-V'yi kıyaslayan çalışmada toplam 101 hasta randomize olarak 2 gruba ayrılmıştır. Görüntü kalitesi ve manevra kabiliyeti açısından yap1lan kıyaslamada URF-V daha üstün bulunurken dayanıklılık aşısından her iki f-URS arasında fark bulunamamıştır (9).

\section{Tek kullanımlık dijital f-URS'ler}

Son dönemde ekonomik olarak daha avantajlı olma iddiasıyla tek kullanımlık dijital f-URS'ler piyasaya çıkmıştır. 


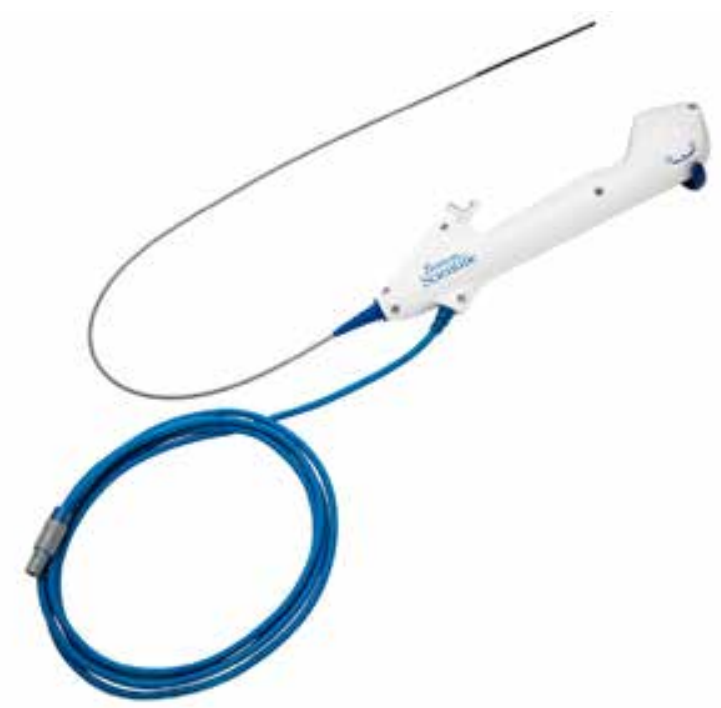

Resim 3: LithoVue ${ }^{\mathrm{TM}}$ tek kullanımlık dijital f-URS

LithoVue $^{\mathrm{TM}}$ (Boston Scientific, ABD), NeoFlex (Neoscope, ABD), Uscope (Zhuhai Pusen Medical Technology, Çin) ve AnQing EU-scope (Anqing Medical, Çin) halen piyasadaki dijital disposible f-URS çeşitleridir (Şekil 3). 7.7F distal uç kalınlığına sahip LithoVue ${ }^{\text {rws }}$ nin kullanıldığı Proietti ve ark. tarafından yapılan kadavra modeli çalışmasında tekrar kullanılabilir dijital f-URS'lerle kıyaslanabilir sonuçlar elde edilmiştir (25). Tek kullanımlık aletlerde sterilizasyon, tamir gibi masrafların olmaması avantajdır. Yine alt kaliks taşları gibi zor vakalarda maksimal defleksiyonda fazla endişe yaşamadan kullanmak mümkündür. Günümüzde in-vitro ve in-vivo olarak yeterli düzeyde çalışma yapılmış olan tek kullanımlık dijital f-URS sadece LithoVue ${ }^{\mathrm{TM}}$ dir (26-28). Bu çalışmalarda LithoVue $^{\mathrm{TM}}$ üst üriner sisteme erişim, dijital görüntüleme kalitesi, manevra kabiliyeti ve defleksiyon oran açısından tekrar kullanılabilir dijital f-URS'ler ile karşılaştırılabilir düzeyde bulunmuştur. Ancak diğer yeni tek kullanımlık cihazların ekonomik avantajını, özellikle ülkemizde tam olarak belirleyebilmek için henüz yeterli çalışma mevcut değildir.

\section{Dijital f-URS'lerin maliyeti}

Kuşkusuz dijital f-URS'lerin fiberoptik olanlara göre önemli farklarından biri de daha yüksek olan maliyetleridir. Binbay ve ark. 2010 yllinda fiberoptik ve dijital f-URS'lerin maliyetlerini kıyasladıkları çalışmalarında alım maliyeti açısindan fiberoptik alet için 30.000 , dijital alet için ise $90.000 \$$ gibi oldukça farklı rakamlara ulaşırken, tamir maliyeti açısindan ise fiberoptik aletlerde $20.000 \$$, dijital aletlerde ise $36.000 \$$ şeklinde bir fark olduğunu belirtmişlerdir (13). 2018 yılında yine ülkemizden Temiz ve ark. tarafından yapılan bir maliyet karşılaştırmasında ise fiberoptik Storz FLEX- $X^{2}$ ve dijital Wolf COBRA Vision karşılaştııılmış, sırasıyla 29.000\$ $58.000 \$$ maliyetlerine rağmen operasyon sonuçları, dayanıklılık ve maliyet-etkinlik açısından belirgin bir fark bulunamamıştır (29). Zaman içinde dijital f-URS fiyatlarında gerileme olmasına rağmen ülkemizdeki maliyetleri hala 50.000\$ üzerindedir. Diğer taraftan yurtdışında yapılan çalışmalar tek kullanımlık f-URS'lerin yüksek vaka volümlü merkezler dişında daha ekonomik olabileceğini işaret etmektedir (30).

\section{SONUÇ}

Dijital f-URS'lerin sunduğu yüksek görüntü kalitesi ve NBI gibi ek özellikler maliyetlerininin daha yüksek olmasından kaynaklanan devantajı geride bırakıyor gibi görünmektedir. Distal uçlarının daha kalın olması ise bazı vakalarda kısitlılık yaratabilmektedir. Bu nedenle yüksek volümlü merkezlerde dijital yanında daha düşük kalibreli fiberoptik bir f-URS'nin de bulunmasında fayda vardır. Teknolojideki hızlı gelişimin dijital f-URS'lere yansımasıyla birlikte ileride daha düşük kalibreli ve daha uzun ömürlü modellerin ve daha düşük maliyetli tek kullanımlık dijital f-URS'lerin kullanıma sunulması muhtemeldir.

\section{Kısaltmalar}

CCD: charge-coupled device, CMOS: complementary metal oxide semiconductors, F: French.

\section{Kaynaklar}

1. Marshall VF. Fiberoptics in Urology. J Urol 1964;91:110114.

2. Bagley DH, Huffman JL, Lyon ES. Flexible ureteropyeloscopy: diagnosis and treatment in the upper urinary tract. J Urol 1987;138(2):280-285.

3. Pietrow PK, Auge BK, Delvecchio FC, Silverstein AD, Weizer AZ, Albala DM, Preminger GM. Techniques to maximize flexible ureteroscope longevity. Urology 2002;60(5):784-788.

4. Rosa M, Usai P, Miano R, Kim FJ, Finazzo AE, Bove $\mathrm{P}$, Micali S; International Translational Research in Uro-sciences Team (ITRUST). Recent findings and new Technologies in nephrolithiasis: a review of the recent literature. BMC Urol 2013;16(13):10.

5. Al-Qahtani SM, Geavlette BP, de Medina SG, Traxer OP. The new Olympus digital flexible ureteroscope (URF-V): initialexperience. Urol Annals 2011;3:133-137.

6. Beiko DT, Denstedt JD: Advances in ureterorenoscopy. Urol Clin North Am 2007;34:397-408.

7. Cauberg EC, de Bruin DM, Faber DJ, van Leuween TG, de la Rosette JJ, de Reijke TM. A new generation of optical diagnosis for bladder cancer: technology, diagnostic accuracy and future applications. Eur Urol 2009;56:287-296.

8. Traxer O, Geavlete B, de Medina SG. Narrow-band imaging digital ureteroscopy in detection of upper urinary tract transitional-cell carcinoma: intial experience. J Endourol 2011;25:19-23.

9. Shah K, Monga M, Knudsen B. Prospective randomized trial comparing 2 flexible digital ureteroscopes: ACMI/ Olympus Invisio DUR-D and Olympus URF-V. Urology 2015;85:1267-1271.

10. Wetherell D, Ling D, Ow D et al: Advances in ureteroscopy. Transl Androl Urol 2014;3:321-327.

11. Somani BK, Al-Qahtani SM, de Medina SD et al. Outcomes of flexible ureterorenoscopy and laser fragmentation for renal stones: comparison between digital and conventional ureteroscope. Urology 2013;82:1017-1019.

12. Ülker V, Erol B, Bazmanoğlu E, Esen T. 2cm'e kadar olan böbrek taşlarının tedavisinde fleksibl üreterorenoskopi ve Holmiyum lazer litotripsi. Turk Urol D 2006;32:355-358. 


\section{DIJITAL FLEKSIBL ÜRETERORENOSKOPLAR}

13. Binbay $M$, Yürük E, Akman T, Özgür F et al. Is there any difference in outcomes between digital and fiberoptic flexible ureterorenoscopy procedures? J Endourol 2010;24:1929-1934.

14. Multescu R, Geavlete B, Georgescu D, Geavlete P. Conventional fiberoptic flexible ureteroscope versus fourth generation digital flexible ureteroscope: a critical comparison. J Endorol 2010;24:17-21.

15. Bach C, Nesar S, Kumar $P$ et al. The new digital ureteroscopes:"size does matter": increased access sheath use! Urol Int 2012;89:408-411.

16. $\mathrm{Ng} \mathrm{YH}$, Somani BK, Dennison A et al. Irrigant flow and intrarenal pressure during flexible ureteroscopy: the effect of different access sheaths, working channel instruments and hydrostatic pressure. J Endourol 2010;24:1915-1920.

17. Wiland D, Canales BK, Monga M. Medical devices used for ureteroscopy for renal calculi. Expert Rev Med Devices 2006;3:73-80.

18. Xavier K, Hruby GW, Kelly CR, Landman J et al. Clinical evaluation of efficacy of novel optically activated digital endoscope protection system against laser energy damage. Urology 2009;73:37-40.

19. Andonian S, Okeke Z, Smith AD. Digital ureteroscopy: the next step. J Endourol 2008;22:603-606.

20. Bratslavsky G, Moran ME. Current trends in ureteroscopy. Urol Clin North Am 2004;31:181-187.

21. Afane, JS, Olweny EO, Bercowsky E et al. Flexible ureteroscopes: a single center evaluation of the durability and function of the new endoscopes smaller than 9 Fr. J Urol 2000;164:1164-1168.

22. Traxer O, Dubosq F, Jamali K, Gattegno B et al. Newgeneration flexible uretero-renoscopes are more durable than previous ones. Urology 2006;68:276-279.

23. Mustescu R, Geavlete B, Geavlete P. A new era: performance and limitations of latest models of flexible ureteroscopes. Urology 2013;82:1236-1239.
24. Multescu R, Geavlete B, Georgescu D, Geavlete P. Improved durability of flex-Xc digital flexible ureteroscope: how long can you expect it to last? Urology. 2014;84(1):32-35.

25. Proietti S, Dragos L, Molina W et al. Comparison of new single-use digital flexible uteteroscope versus nondisposible fiber optic and digital ureteroscope in a cadaveric model. J Endourol 2016;30:655-659.

26. Butticè $S$, Sener TE, Netsch C, Emiliani E, Pappalardo R, Magno C. LithoVue ${ }^{\mathrm{TM}}$ : A new single-use digital flexible ureteroscope. Cent European J Urol 2016; 69: 302-305.

27. Proietti S, Dragos L, Molina W, Doizi S, Giusti G, Traxer O. Comparison of new single-use digital flexible ureteroscope versus nondisposable fiber optic and digital ureteroscope in a cadaveric model. J Endourol. 2016;30: 655-659.

28. Wiseman O, Keeley F, Traxer O, Preminger G. A single-use disposable digital flexible ureteroscope (LithovueTM) compared to a nondisposable fibre-optic flexible ureteroscope in a live porcine model. Eur Urol Suppl. 2016;15:eV76.

29. Temiz MZ, Colakerol A, Ertas K, Tuken M, Yuruk E. Fiberoptic versus digital: A comparison of durability and cost effectiveness of the two flexible ureteroscopes. Urol Int 2018;21:1-6.

30. Martin CJ, McAdams SB, Abdul-Muhsin H, et al. The economic implications of a reusable flexible digital ureteroscope: a cost-benefit analysis. J Urol 2017;197:730735.

Yazışma Adresi:

Volkan Ülker,

Sağlık Bilimleri Üniversitesi, Tepecik Eğitim ve Araştırma Hastanesi, Üroloji Kliniŏgi, İzmir

Tel: +90 5324324763

e-mail:ulkerv@hotmail.com 